\section{Italian Science Mirrors EC Policies}

Professor C. Rizzuto, Director of the National Interuniversity Consortium for the Physics of Matter (Consorzio INFM in Italian) and Chairman of the European Community's Human Capital and Mobility CODEST review committee for physics discussed the evolution of Italian science policy with the Editor.

\section{Reflecting EC Goals}

It may appear that Italy lacks a coherent policy for science owing to the country's recent political vacuum and the appointment of a new Minister for Universities, Research, Science, and Technology. Professor Rizzuto thinks this is not the case. There is a "continuity in basic thinking" because national activities must referenced to the "international situation" (specifically the EC) and to entry into Europe. So EC goals to speed up economic growth (as echoed in the familiar jargon - pre-competitive to competitive; basic research to market, etc.) gives political power to the research ministry (MURST). The science policy is articulated in a three-year plan which has been drafted by the National Science and Technology Council (CNST) set up by the former Minister in 1991.

Measures reflecting the new policy have already been implemented. For instance, industrial research funding mirrors $\mathrm{EC}$ initiatives to improve economic competitivity. The CNST has developed for the science minister Strategic Plans with long-term objectives covering several fields (e.g., telecommunications, materials). They follow on from the National Research Council's (CNR) concept of 3-4 year Finalised Projects for technology development in specific fields (e.g., solid state, electronics, superconductors) that have allowed the CNR to become more industrially relevant.

Within the Strategic Plans, $20 \%$ of grants to industry must be used for training. The INFM which groups the activities of the 1800 members of all the universities operating in physics of matter (loosely put as "low energy physics") has been able to respond by handling an increasing number of short-term "human capital" contracts. The INFM acquired the necessary flexibility and legal framework under the 1986 law which created the consortium from four earlier university consortia. The large CNR (1992 budget: 2000 MECU) which covers a $360^{\circ}$ spectrum of disciples via many research centres does not have the same possibilities. However, this may change as both the CNR and the universities are "adapting to the temporary contract system" that allows students, young scientists and technical staff to be supported on projects. Traditionally, it has been difficult to support Italian Ph.D. students on university research budgets. Some $70 \%$ of the total of these budgets now comes from the CNR and $30 \%$ (640 MECU) from the "60/40" MURST grants $160 \%$ to the university $/ 40 \%$ to the project) through the CNST - both channels having remained constant for 5 years following a short period of increasing and much needed investment in university research. Before the new university law of 1985 , the CNR used to provide $100 \%$ so without a budget the science minister could only coordinate.
Another measure reflecting the new policy promotes "run of". If a group has an EC grant it finds it easier to obtain government funding. Related to this is "pre-step" funding to acquire critical capabilities allowing EC contracts to be sought. The overall effect has been to raise Italian participation in EC science programmes from an "episodic" $6 \%$ to something close to the juste retour $15 \%$ level (although this is not required by EC rules).

\section{Institute Status to be Sought}

There has been much discussion about changing the status of the INFM to a fullyfledged national institute equivalent to the much larger INFN for nuclear physics (1992 budget: $900 \mathrm{MECU}$ ). Professor Rizzuto indicated that there was approval in principle in the CNST for the transformation and that a bill will soon be submitted to Parliament or to the government.

It has been argued that INFM has "an independent position with good possibilities" so why have a second national institute in physics in addition to the INFN when other fields have nothing. The reality is that physics necessarily involves large facilities covering several fields which must be integrated into user communities. Second, why antagonise other physics disciplines notably astronomy - who may also want their own institutes? Most Italian astronomy facilities are within the CNR which risks budget cuts if astronomy became independent. Professor Rizzuto argues that the spending on science must increase to European norms so the CNR would not risk too much by according institute status to INFM. He notes that Italian support for each university scientist in physics of matter 0.03 MECU per head for 1992 not including overhead) is only about $1 / 4$ of the levels in the UK, France and Germany. The CNST national plans aim to rectify this (e.g., a doubling of government spending in materials in 3-5 years). But, of course, science may not be a primary concern as Italy must soon reduce the government deficit to enter EC monetary union. The difficulties show up in the

The INFM operates from the Badia Benedettina di S. Andrea (shown below), a former monastery founded in the 14th century and located close to Genoa's main airport.

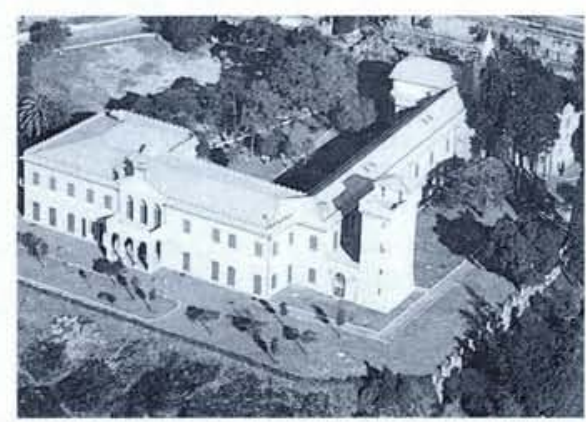

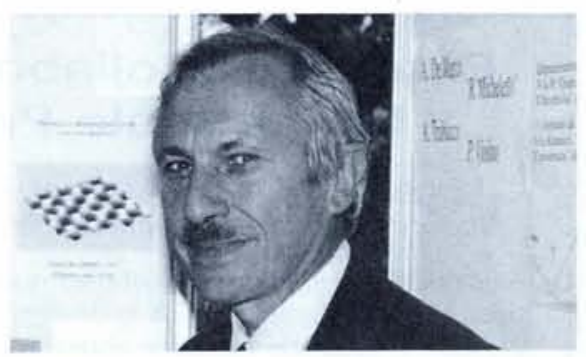

Professor C. Rizzuto at the 1992 annual INFM Physics of Matter conference in Genoa on 1-5 June 1992. The conference was organized this year with the CNR and the University of Genoa as part of the Columbus celebrations.

universities' research budget which remains constant.

Institute status would imply more regular government support as well as independent operation and complete responsibility strong "motivations" to unite a fragmented community of condensed matter physics, chemical physicists, etc. organized into the INFM's seven sub-groups, each using the unique INFM peer review system for selecting projects to receive support.

\section{A de facto Institute}

INFM is already a de facto national institute because from this year its budget of 91.2 MECU includes 40 MECU for building the 600 MECU ELETTRA synchrotron in Trieste. The government's committed participation of $350 \mathrm{MECU}$ used to pass through the CNR, together with that for the ILL neutron source in Grenoble (a total of 60-80 MECU or $3-4 \%$ of the CNR budget). An INFM proposal to handle the ILL contribution is now being considered by the CNR, and the INFM envisages proposals to participate in new neutron spallation sources (Austron and the ESS - see EN 23 [1992] 60) other than ISIS in the UK. The INFM also represents the universities in their building of instruments for the ESRF synchrotron under construction in Grenoble. Finally, the consortium operates a national lab for surfaces and catalysis in support of ELETTRA.

Professor Rizzuto argues that the INFM link to large facilities is essential because one must finance these facilities through users and not directly so as to avoid a "gap with users". Secondly, there is "added value" since research groups are "activated" to become users. He gave CERN as a good model.

\section{ITALIAN ICF RESEARCH Apology}

In the May 1992 issue of Europhysics News, the work of the Italian National Agency for New Technology, Energy and the Environment (ENEA) at Frascati on inertial confinement fusion (ICF) was incorrectly attributed to the INFN Frascati. ENEA has worked on ICF since the 1960's, mainly on the interaction of laser light with matter, and operates the $A B C$ two-beam, neodymium laser system (100 J per beam). We apologise for incorrectly attributing the work of S. Atzeni presented on the front cover and ENEA contributions to ICF target research discussed on page 91 . 